\title{
Decision Support Concerning Demand Response Programs Design and Use - A Conceptual Framework and Simulation Tool
}

\author{
Pedro Faria* and Zita Vale \\ Knowledge Engineering \& Decision Support Research Centre (GECAD), School of Engineering - Polytechnic Institute of Porto \\ (ISEP/IPP), Porto, Portugal
}

Received: 4 Jun. 2013, Revised: 28 Sep. 2013, Accepted: 29 Sep. 2013

Published online: 1 Jan. 2014

\begin{abstract}
Demand response can play a very relevant role in the context of power systems with an intensive use of distributed energy resources, from which renewable intermittent sources are a significant part. More active consumers participation can help improving the system reliability and decrease or defer the required investments. Demand response adequate use and management is even more important in competitive electricity markets. However, experience shows difficulties to make demand response be adequately used in this context, showing the need of research work in this area. The most important difficulties seem to be caused by inadequate business models and by inadequate demand response programs management. This paper contributes to developing methodologies and a computational infrastructure able to provide the involved players with adequate decision support on demand response programs and contracts design and use. The presented work uses DemSi, a demand response simulator that has been developed by the authors to simulate demand response actions and programs, which includes realistic power system simulation. It includes an optimization module for the application of demand response programs and contracts using deterministic and metaheuristic approaches. The proposed methodology is an important improvement in the simulator while providing adequate tools for demand response programs adoption by the involved players. A machine learning method based on clustering and classification techniques, resulting in a rule base concerning DR programs and contracts use, is also used. A case study concerning the use of demand response in an incident situation is presented.
\end{abstract}

Keywords: Demand response, decision support system, distributed generation, distribution system, simulation.

\section{Introduction}

One area expected to grow in the scope of electricity markets is Demand Response (DR), as it appears as a very promising opportunity for consumers and brings several advantages for the whole system [1,3]. This is due to the fact that power systems infrastructure is highly capital intensive and demand response is one of the cheaper resources available to prevent investment needs, by peak-shaving and strategic load curtailment in congestion situations [4]. On the other hand, demand response programs can provide the system operator with a determined load curtailment capacity which is highly valuable to deal with unexpected changes in both supply and demand levels. The actual state of demand response around the world is summarized in [5]. DR in U.S. wholesale markets, reporting an increase of $10 \%$ in the number of entities offering dynamic pricing tariffs to retail customers from 2006 to 2008, is described in [6]. However, demand response is not being as successful as expected in the context of competitive markets. In some cases, the electricity markets implementation even caused a reduction in demand participation $[7,8,9]$.

Practically speaking, demand response has been implemented in various electricity markets and has proved to bring relevant benefits to market players. Furthermore, demand response opportunities are normally considered vital for negotiating contracts between retailers and customers in future smart grids. However, till the present, demand side has been unable to use all the business opportunities in the scope of electricity markets in a satisfactory way. Efficient demand response management requires new approaches to deal with the complex interdependencies existing between electricity prices and volumes.

\footnotetext{
* Corresponding author e-mail: pnsfaria@gmail.com
} 
The difficulties concerning demand response participation appear even for large demand side players and obviously apply to small players. Aggregation is being more and more used, so that electricity markets players can join their resources and efforts to obtain competitive advantage in electricity markets [10,11]. However demand response has very specific needs that even large aggregators face serious difficulties in dealing with. This shows the need to address DR as a priority, providing electricity markets players with adequate DR programs, contracts and business models.

The model presented in this paper aims at extending the already obtained results $[11,12,13,14,15,16,17]$, contributing to overcome present demand response limitations. The main objective is to provide the involved players with decision-support concerning DR programs and contracts use and adoption.

The participation in DR programs can be voluntary or mandatory. Presently, implemented DR programs are voluntary [18], although some studies report important advantages of the mandatory approach [8].

Demand response programs can be divided in two wide groups, namely price-based demand response and incentive-based demand response [19]. The former is related with changes in customers consumption in response to variations in energy prices. The latter includes programs involving customers incentives that are additional to their electricity rates, which may be fixed or time varying.

DR programs can be divided by economic (demand bidding) and operational (reliability) purposes. Combining these two purposes, ancillary services can include load demand bids to participate in those services which are crucial for the system operation.

After this introductory section, Section 2 presents the developed decision support system and Section 3 concerns the implemented decision-support model. After the case-study of Section 4, the main conclusions of the work exposed in the paper are presented in section 5 .

\section{Decision-support system}

The methodology presented in this paper has been implemented in a decision support system integrated in a demand response simulator, DemSi [12,13,14,15], developed by the authors of the paper. The simulator has important capabilities in what concerns the DR programs use evaluation and has been updated to include the tools necessary to simulate and support the decision concerning DR programs adoption, as described in this paper.

The present section makes a brief description of the simulator, as well as the explanation of the players activities supported by the simulator, and an introduction to the existing demand response programs models.

\subsection{Demand response simulator}

The simulator, as shown in the functional diagram of Figure 1, includes an optimization module for the application of DR programs and contracts using deterministic and metaheuristic approaches.

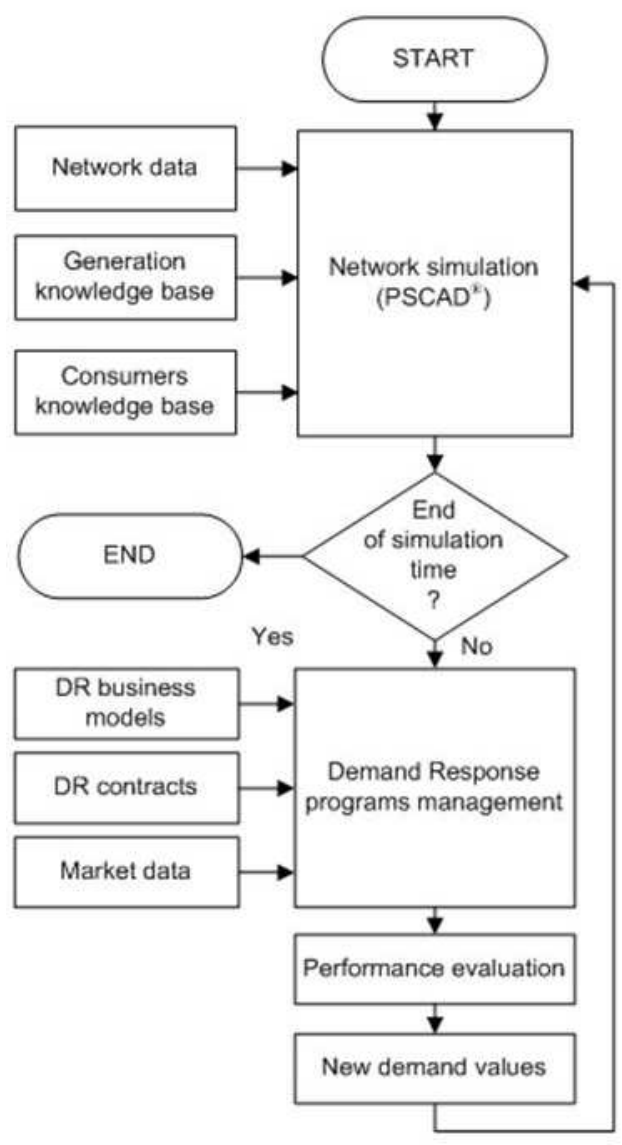

Fig. 1 DemSi functional diagram.

The simulator also includes a realistic power system simulation module, based on PSCAD, to undertake the optimization results technical validation. Presently, the simulator has several limitations, namely it only is capable of network simulation considering a priori defined load reduction in the context of a defined DR program.

\subsection{Players}

The implementation of electricity markets gives place to the existence of several players. The basic players of an electricity market are the consumers and the producers since the objective is to supply the consumers demand. Traditionally, this has often been achieved by vertically 
integrated companies supplying to consumers the energy provided by producers. However, in the scope of present electricity markets diverse players such as DNO (Distribution Network Operator), TSO (Transmission System Operator), MO (Market Operator), VPP (Virtual Power Players), CSP (Curtailment Service Provider), and Retailers, interact to accomplish individual and common goals. Figure 2 shows the relationships between these players. In this figure, black thick arrows represent the physical electricity flows, and the grey arrows represent financial electricity exchanges.

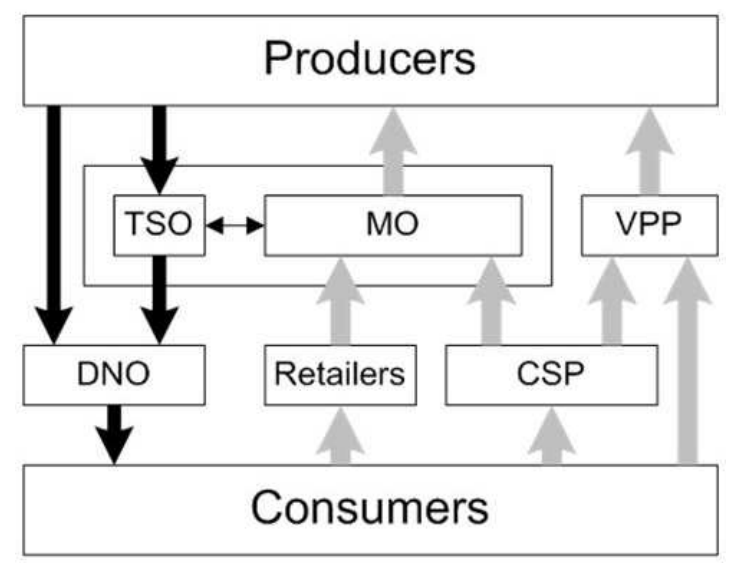

Fig. 2 Relationships between the electricity market players (adapted from [21]).

Depending on the size and location of the loads, energy can be delivered to the consumers by a DNO or a TSO. For most consumers, the TSO delivers energy to DNOs and these deliver energy to the consumers. A brief description of the players in the figure is presented in [21].

Considering the participation of the new distributed resources connected to the networks in electricity markets, requires a new type of player. Small players owning distributed resources do not have the capability of participating in a competitive environment. VPPs can aggregate several small-scale energy resources, as distributed generation, storage, and demand response, managing these resources and making them able to participate in electricity markets.

Another special player only aggregating consumers DR participation, the CSP, is needed in order to make the small consumers able to participate in DR programs designed for large consumers. Small consumers without the reduction capacity required by the DR program managing entity (usually an ISO) make a contract with a CSP, which aggregates several small consumers DR and participates in the DR program.

\subsection{Demand response programs and contracts models}

Demand response programs can be divided in two wide groups, namely price-based demand response and incentive-based demand response [8].

Price-based demand response is related to the changes in energy consumption by customers in response to the variations in their purchase prices. This group includes Time-Of-Use (TOU), Real Time Pricing (RTP) and Critical-Peak Pricing (CPP) rates. For different hours or time periods, if the price varies significantly, customers can respond to price variations with changes in energy use. Their energy bills can be reduced if they adjust the time of the energy usage taking advantages of lower prices in some periods or reduce consumption when prices are higher. Currently, the response to price-based demand response programs by adjusting the time of consumption is entirely voluntary. However, some advantages of mandatory response can be found. An important demand-side resource that can be considered independently, but not necessarily disconnected from the above described DR programs is the energy efficiency, which has to be considered in the long time system planning.

\section{Implemented decision-support model}

As described in Section 2, DemSi has important capabilities in what concerns the DR programs use. The present section presents an improvement of the simulator and of the decision-support system, as the main contribution of the paper, in order to include the decision-support concerning DR programs adoption. This section presents the explanation of the need of the developed machine learning module which is of high interest for the implementation of the DR programs adoption decision support, and the consumers performance evaluation required for the determination of the effective participation of the consumers in a demand response program event.

The functioning of the system is illustrated in the diagram presented in Figure 3. The system includes two main sub-modules, concerning the contracts use and the contracts adoption. For programs adoption, decision support will consider DR programs and contract evaluation. The modules of the system depicted in Figure 3 in grey color are the ones concerning the demand response programs use and the power system simulation. Moreover, those modules include the optimization, including both deterministic and heuristic methods, of the different players behavior in order to support their decision concerning DR programs use and adoption. The electricity markets structures are also included for the characterization of the DR programs and context simulation. 


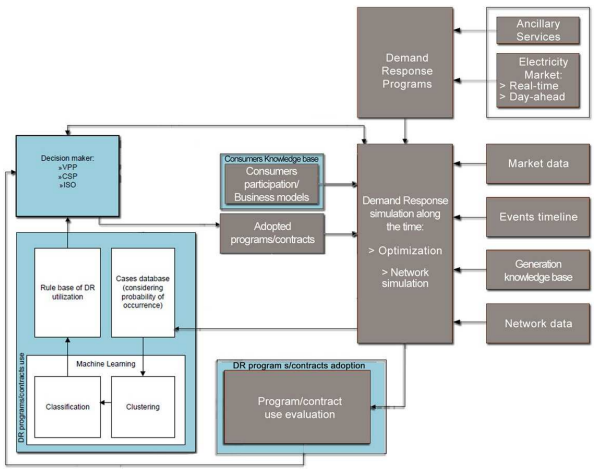

Fig. 3 Demand response decision-support system.

The modules depicted in light blue constitute the improvement of the decision support presented in this paper and are the ones regarding the decision-support for DR programs adoption. An adequate study of the DR programs adoption requires large amounts of data to be analyzed. Regarding this aspect, the system has been improved with a machine learning module (described in section 3.1) and a consumers knowledge base.

In order to address an adequate evaluation of the consumers effective participation in demand response events, the system has been improved with consumers performance evaluation tools, as described in section 3.2.

\subsection{Machine learning module}

This module is the main addition to be included in the DR simulator. The main objective is to study and determine the data-mining techniques adequate for the consumers participation in DR programs classification. With a large diversity of consumers acting in DR programs, with different types (domestic, commerce, industry, services, etc.), different peak consumption power, different daily load demand profile, and with different goals/awareness in the scope of that programs, new classification techniques are required. This classification is important for the design by an ISO, for the participation by a VPP, and for the bidding by a CSP in a DR program.

\subsection{Consumers performance evaluation}

The reduction of load demand consumption is always subjective since consumers could intentionally increase consumption before a known demand response event to pretend that the load demand was reduced during the demand response event. To avoid these cases, performance evaluation methods have been developed. The methodology developed in this paper includes a baseline performance evaluation method.
A baseline is an estimate of the electricity that would have been consumed by a demand resource in the absence of a demand response event. The baseline is compared with the actual metered electricity consumption during the demand response event to determine the demand reduction value. Depending on the type of demand response product or service, baseline calculations may be performed in real-time or after-the-fact. The system operator may offer multiple baseline models and may assign a demand resource to a model based on the characteristics of the demand resources load. Alternatively, it may allow the demand resource to choose a performance evaluation model consistent with its load characteristics from a predefined list. A baseline model is the simple or complex mathematical relationship found to exist between baseline window demand readings and independent variables. A baseline model is used to derive the baseline adjustments, which in turn is used to compute the demand reduction value. An independent variable is a parameter that is expected to change regularly and have a measureable impact on demand. Figure 4 illustrates the concept of baseline relative to a demand response event.

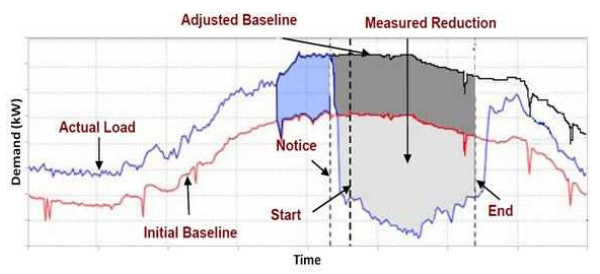

Fig. 4 Example Baseline and Performance Measurement for Demand Response Asset [22].

For a given time interval $t$, the initial baseline $b t$ is calculated as the average demand among the 5 days with the highest energy usage out of the prior 10 non-event days (this calculation is performed for each interval time interval $\mathrm{t}$ during the demand response event), as in equation 1 .

$$
b_{t}=\frac{\left(C_{t d 1}+C_{t d 2}+C_{t d 3}+C_{t d 4}+C_{t d s}\right)}{5}
$$

The adjustment factor $a$ is calculated as the difference in observed demand and the estimated baseline, for a calibration period starting two hours before event notification, with a minimum adjustment of 0 , as in equation 2. This factor is calculated for each time interval $t$.

$$
a_{t}=\max \left\{\frac{\left[\left(C_{t-1}-b_{t-1}\right)+\left(C_{t-2}-b_{t-2}\right)\right]}{2}, 0\right\}
$$

The total performance $p$ is measured as the integrated difference between the sum of the baseline $b$ and the adjustment factor $a$ minus the consumption $c$, for each 
interval $t$ over an event period beginning at time 0 and ending at time $e$, as seen in equation 3 .

$$
p=\sum_{t=0}^{e}\left(b_{t}+a_{t}\right)-C_{t}
$$

The capacity-setting performance pavg is simply the average performance during all intervals of the demand response event for which the program rules stipulate that performance is mandatory, as in equation 4.

$$
p_{\text {avg }}=\frac{\sum_{t=0}^{e}\left(b_{t}+a\right)-C_{t}}{e}
$$

It is important to note that the day-of load adjustment period is the two hours period prior to event notification instead of the two hours period prior to the event start.

\section{Case study}

The present case study shows the application of the consumers performance evaluation to the case study presented in [12]. This section includes the explanation of a DR program model as well as the scenario characterization and the obtained results.

\subsection{Demand response program model}

The growing use of Distributed Generation (DG) has changed the way that electricity networks are operated. A fault originating a lack of supply that causes the existence of an island can be a good opportunity for both DR and DG to be used, evidencing their real value. Figure 5 shows an example of a distribution network connected to a larger upstream network through line 0-1.

When a fault occurs in this line, there will be a lack of supply from the upstream network, and the envisaged distribution network will operate in island mode.

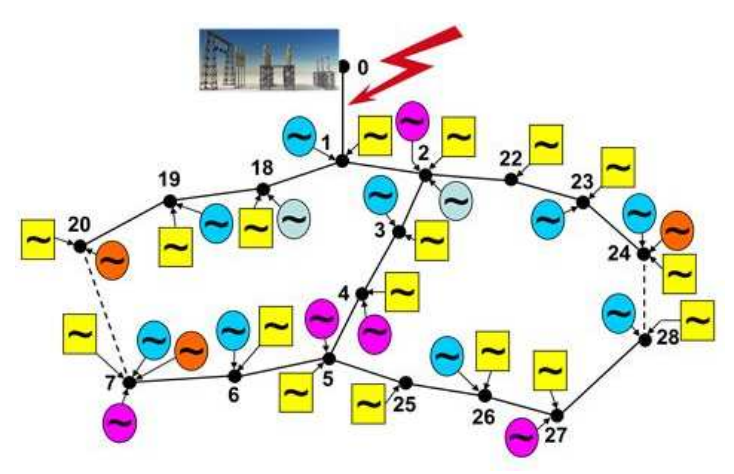

Fig. 5 Example of network islanding operation.

An adequate use of the available resources can make possible to supply some important loads and reduce the economic impact of the fault. When facing a generation shortage (e.g. in case of an incident), the distribution network operator makes use of flexible contracts and/or Real-Time Pricing (RTP) to condition consumers behavior. When such situation occurs, the solution can be found in two phases:

-Phase I The available energy production is evaluated and it is analyzed if it is sufficient to supply the critical loads. These loads should never be shed, unless it is absolutely impossible to supply them, due to security and/or economic reasons. The critical load status should be adequately addressed in the contracts between these loads owners and their suppliers. If all critical loads can be satisfied and there is a surplus of energy, the way this energy should be used, is determined in phase II;

-Phase II The remaining loads that should be completely or partially supplied are determined using an optimization approach. This aims at minimizing the costs of the incident, from the suppliers and the distribution network operator point of view.

Regarding the demand response, loads differ mainly on the conditions they impose for eventually being curtailed or reduced under specific situations. This determines if each load must be considered in Phase I or in Phase II, as well as the Value Of Lost Load (VOLL) established in the contract. By default, DemSi considers three different typical load profiles, as follows:

-Critical Loads (CL) which should be supplied in every situation. When not supplied, these loads receive high compensation values, as determined by the contracts between their owners and their suppliers;

-Clients with Flexible Supply contracts (FS), which have hired the priority of their circuits and/or loads in case of supply shortage. The distribution network operator can control each of these clients overall load or some of its circuits. Financial terms for this supply flexibility are established in the supply contracts;

-All other loads, which are considered Regular Loads (RL).

\subsubsection{Mathematical formulation}

As mentioned above, Phase II aims at minimizing the costs of a generation shortage situation. After completing Phase I with all the critical loads supplied, this can be modeled as an optimization problem. The objective function, in (5), is formulated with the aim of minimizing the total cost that the distribution network operator has to pay for non-supplied loads (VOLL). It is important to note that Phase II always corresponds to a situation for which there is a lack of supply.

$$
\begin{aligned}
& \text { Minimize } \\
& O C=\sum_{c=1}^{N c}\left(P_{\operatorname{Red}(c)} \times C_{\operatorname{Red}(c)}+P_{\operatorname{Cut}(c)} \times C_{\operatorname{Cut}(c)}\right)
\end{aligned}
$$


The constraints of the problem are the power balance (6); the maximum curtailment for each consumer (7); and the maximum reduction for each consumer (8). The difference between reduction and curtailment is that the curtailment is the decrease of the total amount of power, whereas the reduction can be of any value between zero and the total considered load. The reduction corresponds to the changes, for example, in the lighting power, in function of the specified luminance needs. The curtailment method corresponds to the elimination of the consumption in a determined consumer, circuit of loads, or load. Both methods require adequate technological means. A certain consumer could have both methods of consumption decrease, or only one of them.

$$
\begin{gathered}
P_{D G}=\sum_{c=1}^{N c}\left(P_{\operatorname{Load}(c)}-P_{\operatorname{Red}(c)}-P_{\operatorname{Cut}(c)}\right) \\
P_{\operatorname{Cut}(c)}=P_{\operatorname{MarCut}(c)}{ }^{*} X_{\operatorname{Cut}(c)}, \\
\forall c \in\{1, \ldots, N c\}, X_{\operatorname{Cut}(c)} \in\{0,1\} \\
P_{\operatorname{Red}(c)}=P_{\operatorname{MaxRed}(c)}, \forall c \in\{1, \ldots, N c\}
\end{gathered}
$$

where,

$O C$ - Total operation costs [m.u.]

$C_{C u t(c)}$ - Cost of power curtailment Cut in the load of consumer c [m.u./kWh]

$C_{R e d(c)}-$ Cost of power reduction Cut in the load of consumer c [m.u./kWh]

$N c$ - Total number of consumers

$P_{D G}$ - Power available from DG [kW] $[\mathrm{kW}]$

$P_{\text {Load(c) }}$ - Initial power of load demand in consumer c

$P_{\operatorname{Red}(c)}$-Power reduction Cut in the load of consumer $\mathrm{c}[\mathrm{kW}]$

$P_{C u t(c)}$-Power curtailment Cut in the load of consumer c $[\mathrm{kW}]$

$P_{\text {MaxRed(c) }}$-Maximum power curtailment Red in the load of consumer c [kW]

$P_{\text {Max Cut (c) }}$-Maximum power curtailment Cut in the load of consumer c [kW]

$X_{C u t(c)}$-Binary variable related to the power curtailment in the load of consumer $\mathrm{c}$

Using this approach and its knowledge about load profiles, the DNO can determine the better way to define and establish supply contracts, at the same time that situations of lack of supply are solved by the use of those contracts.

\subsection{Scenario characterization}

The proposed scenario is based on a distribution network also presented in [12] and depicted in Figure 6. It is a 33 bus distribution network with 32 consumers. As referred, this network is connected to the larger distribution network through bus number 0 . Considering a fault in line $0-1$ that connects bus 0 to the upstream larger distribution network, we will have:
-The considered network turns to an island where DG is the only mean of electricity generation;

-The available DG is not enough to supply all the demand but is enough to supply Critical Loads (CL) and to ensure an adequate amount of reserve;

-The remaining DG must be optimally used to supply additional loads, according to their profiles and contract clauses.

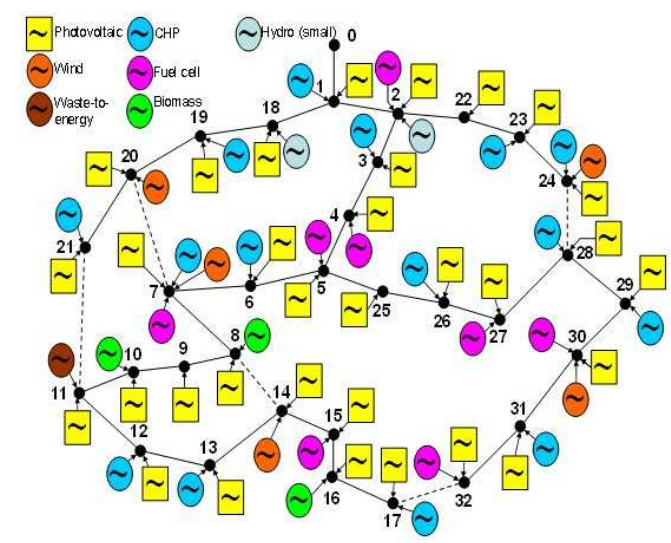

Fig. 633 bus distribution network.

The results obtained in this case study regard the occurrence of the fault in 96 distinct periods of 15 minutes in a complete day. Figure 7 presents the value of the total load and total DG for the first period. DemSi has been used to find the optimization results, and to perform the network simulation.

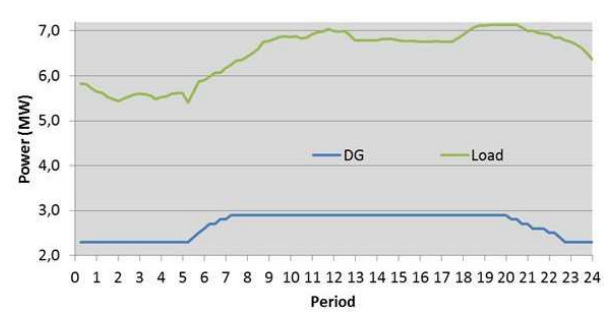

Fig. 7 Load and DG diagram.

\subsection{Results}

The considered fault keeps line $0-1$ out of service, starting in instant 0 and lasting the whole day. The value of the estimated power losses is discounted in the value of the available generation power that is considered to supply the demand. 
Table 1 presents the demand metered data, in $\mathrm{kW}$, for the first period, regarding consumer 1 . These values are the ones necessary for application of equations 1 to 3 in order to perform the consumers Performance Evaluation (PE) described in section 3.2.

Table 2 shows the results obtained for the considered scenario, with and without demand response use, as well as considering the application of the consumers Performance Evaluation (PE) for the first period of 15 minutes. In this period, the total generation is $2300 \mathrm{~kW}$. Table 2 also indicates for the total load connected to each bus (considered as a single consumer) the value in $\mathrm{kW}$ of the Non-Supplied Load (NSL) and the monetary Value Of Lost Load (VOLL).

The case study considers three different situations: with demand response, without demand response, and with demand response including PE. Without DR, the VOLL is calculated according to the value of the unitary VOLL attributed to each individual load. With DR, the VOLL is calculated using the clauses of each load contract; these clauses determine the conditions under which a part of the load may be curtailed. These values are calculated for each individual load; the total value for the load connected to each bus is presented in Table 2 .

In the case with DR and PE, the baseline variables are calculated and then used to determine the effective value of NSL and of the respective VOLL.

This scenario considers two types of flexible contracts (FS1 and FS2), that represents the use of demand response, which only differ on the specific contract clauses (percentage of load that the clients accept to be curtailed and contract tariffs). The loads that have not any type of supply contract are indicated as RL (Regular Loads).

From the presented results, we can conclude that the total VOLL is substantially decreased when considering demand response with a part of the loads with types CL and FS contracts. Moreover, the application of consumers performance evaluation makes possible to determine the effective values of both NSL and VOLL which are significantly lower than the expected ones. It is important to note that the values presented in Table 2 only refer to the VOLL concerning a 15 minutes period. The total annual decrease in the VOLL value depends on the number, duration and characteristics of the faults that cause a lack of supply.

Figure 8 shows the amount of non-supplied load considering and not considering DR, and applying the consumers performance evaluation for the whole day concerning the fault of this case study. The first two curves are very similar because they correspond to the use of the amount of DG available along the day. In what concerns the curve that considers the PE, the values of NSL are lower than the DG available. This leads to a failure in the system supplying the loads as demand still higher than generation after the application of demand response flexible contracts. This leads to the need of including the value of historical baseline PE values in the scheduling of the consumers demand reduction.

In what concerns the two first curves (with and without DR), in spite of the NSL values similarity, the VOLL presents very different values in the two situations as shown in Figure 9.

The results presented in this figure clearly show that an adequate use of DR, through flexible contracts can significantly decrease the VOLL. In addition, including $\mathrm{PE}$ methods makes possible to perform a more accurate determination of VOLL.

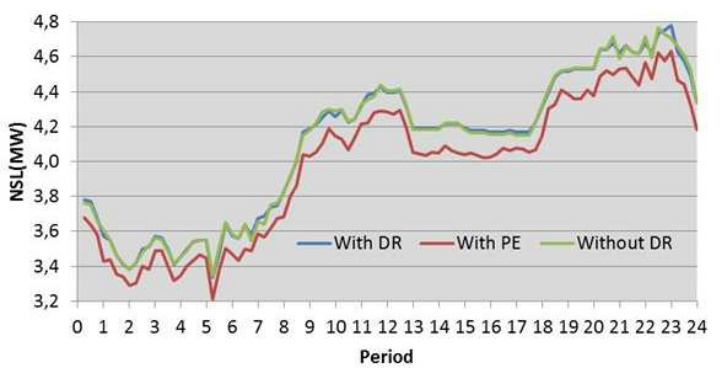

Fig. 8 NSL with and without DR.

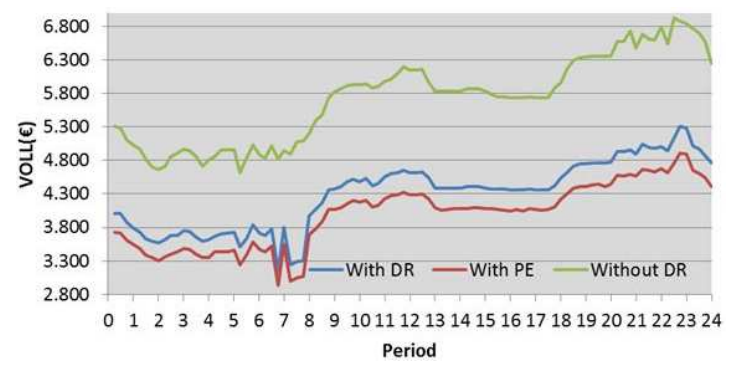

Fig. 9 VOLL with and without DR.

\section{Conclusion}

The demand response concept is a fast evolving topic of crucial importance for the planning and operation of future electricity markets and of power systems in general. Most of DR programs in the past were based on distinct electricity tariffs for different periods of the day. Presently, demand response is evolving to more flexible approaches, able to benefit from the participation of the involved players. The ability of the demand side to play a dynamic, active, and strategic role is especially important under this context. 
Table 1 Consumer 1 demand metered data, for the first period.

\begin{tabular}{|c|c|c|c|c|c|c|c|c|c|c|c|}
\hline \multirow{2}{*}{$\begin{array}{c}\text { Time } \\
\text { interval }\end{array}$} & \multicolumn{10}{|c|}{10 Past non-event days } & Event day \\
\hline & $\operatorname{td} 10$ & $\operatorname{td} 9$ & td8 & $\mathrm{td} 7$ & $\operatorname{td} 6$ & $\operatorname{td} 5$ & $\operatorname{td} 4$ & $\operatorname{td} 3$ & td2 & $\operatorname{td} 1$ & tdo 0 \\
\hline$t-2$ & 33,40 & 34,45 & 36,21 & 34,80 & 35,86 & 34,10 & 28,12 & 21,09 & 35,51 & 33,75 & 35,15 \\
\hline $\mathrm{t}-1$ & 30,22 & 31,17 & 32,76 & 31,49 & 32,44 & 30,85 & 25,44 & 19,08 & 32,12 & 30,53 & 31,81 \\
\hline $\mathrm{t}$ & 31,81 & 32,81 & 34,48 & 33,15 & 34,15 & 32,48 & 26,78 & 20,09 & 33,81 & 32,14 & 33,48 \\
\hline
\end{tabular}

Table 2 Results for the first period.

\begin{tabular}{|c|c|c|c|c|c|c|c|c|c|c|c|c|c|c|c|c|c|c|}
\hline \multirow{3}{*}{ Bus } & \multirow{3}{*}{$\begin{array}{c}\text { Demand } \\
(\mathrm{kW})\end{array}$} & \multicolumn{3}{|c|}{ Without FC } & \multicolumn{4}{|c|}{ With FC } & \multicolumn{10}{|c|}{ With PE } \\
\hline & & \multirow[t]{2}{*}{$\begin{array}{l}\text { NSL } \\
(\mathrm{kW})\end{array}$} & \multirow[t]{2}{*}{\begin{tabular}{|l} 
UVoll \\
$(\epsilon / \mathrm{KWh})$
\end{tabular}} & \multirow[t]{2}{*}{$\begin{array}{l}\text { Voll } \\
(\boxminus)\end{array}$} & \multirow[t]{2}{*}{$\begin{array}{l}\text { Supply } \\
\text { Contract }\end{array}$} & \multirow[t]{2}{*}{$\begin{array}{l}\text { UVoll } \\
(€ / \mathrm{kWh})\end{array}$} & \multirow[t]{2}{*}{$\begin{array}{c}\mathrm{NSL} \\
(\mathrm{kW})\end{array}$} & \multirow[t]{2}{*}{$\begin{array}{l}\text { Voll } \\
\text { (€) }\end{array}$} & \multirow{2}{*}{\begin{tabular}{|c|}
$\begin{array}{c}\text { Due } \\
\text { compsumtion } \\
(\mathrm{kW})\end{array}$ \\
$\mathrm{d} 0 ; 0$ \\
\end{tabular}} & \multicolumn{3}{|c|}{$\begin{array}{c}\begin{array}{c}\text { Metered } \\
\text { consumption } \\
(\mathrm{kW})\end{array} \\
\end{array}$} & \multicolumn{4}{|c|}{$\begin{array}{l}\text { Baseline variables } \\
\qquad(\mathrm{kW})\end{array}$} & \multirow[t]{2}{*}{$\begin{array}{l}\text { NSL } \\
(\mathrm{kW})\end{array}$} & \multirow[t]{2}{*}{$\begin{array}{l}\text { Voll. } \\
(€)\end{array}$} \\
\hline & & & & & & & & & & \begin{tabular}{|l|}
$d 0 ; t 0$ \\
\end{tabular} & $\mathrm{~d} 0 ; t-1$ & $\mathrm{~d} 0 ; \mathrm{t}-2$ & bt & bt-1 & \begin{tabular}{|l|}
$\mathrm{bt}-2$ \\
\end{tabular} & at & & \\
\hline 1 & 169,1 & 169,1 & 7,0 & 295,9 & FS1 & 0,0 & \begin{tabular}{|l|}
135,3 \\
\end{tabular} & 0,0 & 33,8 & 33,5 & 160,6 & \begin{tabular}{|l|}
177,6 \\
\end{tabular} & \begin{tabular}{|l|}
33,7 \\
\end{tabular} & 32,0 & 35,4 & 135,4 & \begin{tabular}{|l|}
135,6 \\
\end{tabular} & 0,0 \\
\hline 2 & 148,9 & 148,9 & 5,0 & 186,2 & RL & 5,0 & \begin{tabular}{|l|}
148,9 \\
\end{tabular} & \begin{tabular}{|l|}
186,1 \\
\end{tabular} & 0,0 & 20,0 & 141,5 & 156,3 & 20,3 & 19,3 & 21,3 & 128,6 & 128,9 & 161,1 \\
\hline 3 & 147,1 & 0,0 & 40,0 & 0,0 & $\mathrm{CL}$ & 40,0 & 0,0 & 0,0 & 147,1 & 148,6 & \begin{tabular}{|l|}
139,7 \\
\end{tabular} & 154,5 & 147,1 & 139,7 & 154,4 & \begin{tabular}{|l|}
0,0 \\
\end{tabular} & 0,0 & 0,0 \\
\hline 4 & 145,5 & 0,0 & 9,0 & 0,0 & $\mathrm{FS} 2$ & 0,0 & 72,8 & 0,0 & 72,8 & \begin{tabular}{|l|}
74,9 \\
\end{tabular} & \begin{tabular}{|l|}
138,2 \\
\end{tabular} & \begin{tabular}{|l|}
152,8 \\
\end{tabular} & 76,1 & 71,5 & 79,9 & \begin{tabular}{|l|}
69,8 \\
\end{tabular} & 70,9 & 0,0 \\
\hline 5 & 94,2 & 94,2 & 7,0 & 164,9 & RL & 7,0 & 0,0 & 0,0 & 94,2 & \begin{tabular}{|l|}
96,1 \\
\end{tabular} & 89,5 & \begin{tabular}{|l|}
98,9 \\
\end{tabular} & \begin{tabular}{|l|}
97,5 \\
\end{tabular} & 92,6 & \begin{tabular}{|l|}
102,4 \\
\end{tabular} & \begin{tabular}{|l|}
0,0 \\
\end{tabular} & 1,4 & 0,0 \\
\hline 6 & 311,1 & 311,1 & 5,0 & 388,9 & FS1 & 0,0 & 248,9 & 0,0 & 62,2 & \begin{tabular}{ll|}
64,7 \\
\end{tabular} & 295,5 & \begin{tabular}{|l|}
326,7 \\
\end{tabular} & \begin{tabular}{|l|}
66,3 \\
\end{tabular} & 63,0 & 69,62 & 244,8 & 246,4 & 0,0 \\
\hline 7 & 308,7 & 308,7 & 6,0 & 463,0 & FS2 & 0,0 & \begin{tabular}{|l|}
154,3 \\
\end{tabular} & 0,0 & 154,4 & \begin{tabular}{|l|}
159,0 \\
\end{tabular} & 293,3 & \begin{tabular}{|l|}
324,1 \\
\end{tabular} & 161,4 & 153,3 & 169,4 & 147,3 & \begin{tabular}{|l|}
149,7 \\
\end{tabular} & 0,0 \\
\hline 8 & 89,3 & 89,3 & 6,0 & 133,9 & RL & 6,0 & \begin{tabular}{|c|}
89,3 \\
\end{tabular} & \begin{tabular}{|c|}
134,0 \\
\end{tabular} & 0,0 & \begin{tabular}{|l|}
10,0 \\
\end{tabular} & 84,8 & \begin{tabular}{|l|l|}
93,8 \\
\end{tabular} & \begin{tabular}{|l|l|}
10,2 \\
\end{tabular} & 9,6 & 10,7 & $\begin{array}{ll}99,2 \\
\end{array}$ & 79,3 & 119,0 \\
\hline 9 & 90,6 & 90,6 & 5,0 & 113,2 & RL & 5,0 & 90,6 & 113,3 & 0,0 & 9,0 & 86,1 & \begin{tabular}{|l|}
95,1 \\
\end{tabular} & \begin{tabular}{|l|}
9,1 \\
\end{tabular} & 8,7 & \begin{tabular}{|l|}
9,6 \\
\end{tabular} & 81,5 & \begin{tabular}{|l|}
81,6 \\
\end{tabular} & 102,0 \\
\hline 10 & 67,0 &, 0 & 30,0 & 0,0 & 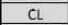 & 30,0 & 0,0 & 0,0 & 7,0 & 69,0 & 63,7 & \begin{tabular}{|l|}
70,4 \\
\end{tabular} & \begin{tabular}{|l|}
67,6 \\
\end{tabular} & 64,2 & 70,0 & 0,0 & \begin{tabular}{|c|}
0,0 \\
\end{tabular} & 0,0 \\
\hline 11 & & & 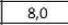 & & & & 72,9 & 0,0 & & 19,1 & 86,5 & 95,7 & \begin{tabular}{|l|}
19,4 \\
\end{tabular} & 18,4 & 20,4 & 71,7 & 72,0 & 0,0 \\
\hline 12 & 91,3 & 91,3 & 7,0 & 159,9 & FS2 & 0,0 & 45,7 & 0,0 & 45,7 & 45,2 & 86,7 & \begin{tabular}{|l|}
95,9 \\
\end{tabular} & \begin{tabular}{|l|}
45,9 \\
\end{tabular} & 43,6 & \begin{tabular}{|l|}
48,2 \\
\end{tabular} & 45,4 & \begin{tabular}{|l|}
46,1 \\
\end{tabular} & 0,0 \\
\hline 13 & 181,3 & 0,0 & 30,0 & 0,0 & $\mathrm{CL}$ & 30,0 & 0,0 & 0,0 & 181,3 & \begin{tabular}{|l|}
177,7 \\
\end{tabular} & 172,2 & \begin{tabular}{|l|}
190,4 \\
\end{tabular} & 180,3 & 170,4 & $\mid 189,4$ & 1,4 & \begin{tabular}{|l|}
4,1 \\
\end{tabular} & 0,0 \\
\hline 14 & 91,1 & 91,1 & 8,0 & 182,1 & RL & 8,0 & 0,0 & 0,0 & 91,1 & 93,4 & 86,5 & \begin{tabular}{|l|}
95,7 \\
\end{tabular} & \begin{tabular}{|l|}
94,8 \\
\end{tabular} & 90,0 & \begin{tabular}{|l|}
99,5 \\
\end{tabular} & 0,0 & 1,4 & 0,0 \\
\hline 15 & 91,1 & 91,1 & 5,0 & 113,8 & & & 91,1 & \begin{tabular}{|l|}
113,9 \\
\end{tabular} & & 7,0 & 86,5 & \begin{tabular}{|l|}
95,7 \\
\end{tabular} & \begin{tabular}{|l|}
7,1 \\
\end{tabular} & 6,7 & 7,5 & 84,0 & \begin{tabular}{|l|}
84,1 \\
\end{tabular} & 105,1 \\
\hline 16 & 91,9 & 0,0 & 50,0 & 0,0 & $\mathrm{CL}$ & 50,0 & 0,0 & 0,0 & 91,9 & 92,8 & 87,3 & \begin{tabular}{|l|}
96,5 \\
\end{tabular} & 94,2 & 89,5 & \begin{tabular}{|c|}
98,9 \\
\end{tabular} & \begin{tabular}{|l|}
0,0 \\
\end{tabular} & \begin{tabular}{|l|}
1,4 \\
\end{tabular} & 0,0 \\
\hline 17 & 135,5 & 135,5 & 3,0 & 101,6 & RL & 3,0 & \begin{tabular}{|l|}
135,5 \\
\end{tabular} & \begin{tabular}{|l|}
101,6 \\
\end{tabular} & 0,0 & 15,0 & \begin{tabular}{|l|}
128,7 \\
\end{tabular} & \begin{tabular}{|l|}
142,3 \\
\end{tabular} & \begin{tabular}{|l|}
15,2 \\
\end{tabular} & 14,5 & 16,0 & 120,3 & 120,5 & 90,4 \\
\hline 18 & 152,4 & 152,4 & & 228,5 & $\$ 1$ & 0,0 & \begin{tabular}{|l|}
121,9 \\
\end{tabular} & \begin{tabular}{|l|}
0,0 \\
\end{tabular} & 30,5 & 30,2 & 144,8 & 160,0 & \begin{tabular}{|l|}
30,6 \\
\end{tabular} & 29,1 & 31,9 & 121,9 & \begin{tabular}{|l|}
122,3 \\
\end{tabular} & 0,0 \\
\hline 19 & 151 & 151,7 & 5 & & $\mathrm{R}$ & 0 & 0,0 & 0,0 & 151,7 & $\mid 157,0$ & 144,1 & 159,3 & 160,9 & 152,9 & 169,0 & 0,0 & \begin{tabular}{|l|}
3,9 \\
\end{tabular} & 0,0 \\
\hline 20 & 151,6 & 151,6 & 5,0 & 189,5 & $\mathrm{RL}$ & 0,0 & \begin{tabular}{|l|}
75,8 \\
\end{tabular} & 0,0 & 0,0 & \begin{tabular}{|c|}
0,0 \\
\end{tabular} & 144,0 & \begin{tabular}{|l|l|}
159,2 \\
\end{tabular} & \begin{tabular}{|l|l|}
0,0 \\
\end{tabular} & 0,0 & \begin{tabular}{|l|l|}
0,0 \\
\end{tabular} & \begin{tabular}{|l|}
151,6 \\
\end{tabular} & \begin{tabular}{|c|}
151,6 \\
\end{tabular} & 0,0 \\
\hline 21 & 151,5 & 151,5 & 3,0 & \begin{tabular}{ll|}
113,6 \\
\end{tabular} & RL & 3,0 & 151,5 & 113,6 & 0,0 & 12,0 & 143,9 & \begin{tabular}{|l|}
159,1 \\
\end{tabular} & \begin{tabular}{|l|}
12,2 \\
\end{tabular} & \begin{tabular}{|l|l|}
11,6 \\
\end{tabular} & \begin{tabular}{|l|l|}
12,8 \\
\end{tabular} & 139,3 & \begin{tabular}{|l|}
139,5 \\
\end{tabular} & 104,6 \\
\hline 22 & 147,3 & 0,0 & & 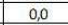 & $\$ 1$ & & \begin{tabular}{|c|}
117,8 \\
\end{tabular} & \begin{tabular}{|l|}
0,0 \\
\end{tabular} & & 30,1 & 139,9 & \begin{tabular}{|l|}
154,7 \\
\end{tabular} & 33,1 & 15,9 & 34,8 & 122,0 & \begin{tabular}{|l|}
124,9 \\
\end{tabular} & 0,0 \\
\hline 23 & 674 & 0,0 & 9, & 0,0 & RL & $\frac{g_{1}}{9,}$ & \begin{tabular}{|l|l|}
674,8 \\
\end{tabular} & \begin{tabular}{|c|}
1518,3 \\
\end{tabular} & 0,0 & 50 & \begin{tabular}{|l|}
641,1 \\
\end{tabular} & $\begin{array}{ll}708,5 \\
\end{array}$ & \begin{tabular}{|l|}
50,8 \\
\end{tabular} & \begin{tabular}{|l|}
48,2 \\
\end{tabular} & \begin{tabular}{|l|}
53,3 \\
\end{tabular} & \begin{tabular}{|l|}
624,1 \\
\end{tabular} & \begin{tabular}{|l|}
624,8 \\
\end{tabular} & \begin{tabular}{|l|l|l|l|l|l|l} 
\\
\end{tabular} \\
\hline 24 & 669,3 & 669,3 & 7,0 & 1171,3 & $\mathrm{RL}$ & 7,0 & 669,3 & 11171,3 & 0,0 & 36,0 & 635,8 & 702,8 & 36,5 & 34,7 & 38,4 & 632,8 & \begin{tabular}{|l|}
633,3 \\
\end{tabular} & 1108,3 \\
\hline 25 & 93,8 & 93,8 & 5, & 117,2 & & & \begin{tabular}{|l|}
93,8 \\
\end{tabular} & \begin{tabular}{|l|}
117,3 \\
\end{tabular} & & 0,0 & 89,1 & \begin{tabular}{|l|}
98,5 \\
\end{tabular} & \begin{tabular}{|l|}
0,0 \\
\end{tabular} & \begin{tabular}{|l|}
0,0 \\
\end{tabular} & 0,0 & \begin{tabular}{|l|}
93,8 \\
\end{tabular} & \begin{tabular}{|l|}
93,8 \\
\end{tabular} & \begin{tabular}{|l}
117,3 \\
\end{tabular} \\
\hline 26 & 93,2 & 0,0 & 25 & 0 & $\mathrm{CL}$ & 5,0 & 0,0 & \begin{tabular}{|l|}
0,0 \\
\end{tabular} & 93,2 & 92,7 & 88,5 & \begin{tabular}{|l|}
97,9 \\
\end{tabular} & \begin{tabular}{|l|}
94,1 \\
\end{tabular} & \begin{tabular}{|l|}
89,4 \\
\end{tabular} & \begin{tabular}{|l|l|}
98,8 \\
\end{tabular} & \begin{tabular}{|l|}
0,0 \\
\end{tabular} & \begin{tabular}{|l|}
1,4 \\
\end{tabular} & 0,0 \\
\hline 27 & 92,2 & 92,2 & 4,0 & 92,2 & $\mathrm{RL}$ & 4,0 & 92,2 & \begin{tabular}{|c|}
92,2 \\
\end{tabular} & 0,0 & 0,0 & 87,6 & \begin{tabular}{|l|l|}
96,8 \\
\end{tabular} & \begin{tabular}{|l|}
0,0 \\
\end{tabular} & \begin{tabular}{|l|} 
\\
\end{tabular} & \begin{tabular}{|l|l|}
0,0 \\
\end{tabular} & \begin{tabular}{|l|}
92,2 \\
\end{tabular} & \begin{tabular}{|l|}
92,2 \\
\end{tabular} & 92,2 \\
\hline 28 & 183,0 & 183,0 & 8,0 & 366,1 & FS2 & & \begin{tabular}{|l|}
91,5 \\
\end{tabular} & 0,0 & & \begin{tabular}{|l|l}
44,2 \\
\end{tabular} & 173,9 & \begin{tabular}{|l|}
192,2 \\
\end{tabular} & \begin{tabular}{|l|}
96,0 \\
\end{tabular} & \begin{tabular}{|l|}
91,2 \\
\end{tabular} & \begin{tabular}{|l|}
99,8 \\
\end{tabular} & 87,5 & \begin{tabular}{|l|l|}
89,4 \\
\end{tabular} & 0,0 \\
\hline 29 & 295,3 & 0,0 & 50,0 & 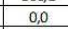 & $\mathrm{Cl}$ & 50,0 & 0,0 & 0 & 295,3 & 309,5 & \begin{tabular}{|l|l}
280,5 \\
\end{tabular} & \begin{tabular}{|l|}
310,1 \\
\end{tabular} & 314,1 & 304,1 & 329,8 & 0,0 & 4,6 & 0,0 \\
\hline 30 & 225,4 & 0,0 & 20,0 & 0,0 & $\mathrm{Cl}$ & 20,0 & 0,0 & 0,0 & 225,4 & 233,7 & 214,1 & 236,7 & 233,0 & 221,4 & 244,7 & 0,0 & 0,0 & 0,0 \\
\hline 31 & 315,1 & 315,1 & 3,0 & 236,3 & RL & 3,0 & \begin{tabular}{|c|}
315,1 \\
\end{tabular} & \begin{tabular}{|c|}
236,3 \\
\end{tabular} & 0,0 & 26,0 & 299,3 & $\begin{array}{l}330,9 \\
\end{array}$ & 26,4 & 25,1 & 27,7 & $|288,7|$ & 289,1 & 216,8 \\
\hline 32 & 89,8 & 89,8 & 5,0 & 112 & RL & 5,0 & \begin{tabular}{|c|}
89,8 \\
\end{tabular} & \begin{tabular}{|l|}
112,3 \\
\end{tabular} & 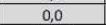 & 4,0 & 85,3 & \begin{tabular}{|c|}
94,3 \\
\end{tabular} & \begin{tabular}{|l|}
4,1 \\
\end{tabular} & 3,9 & \begin{tabular}{|l|}
4,3 \\
\end{tabular} & \begin{tabular}{|l|}
85,7 \\
\end{tabular} & & $\begin{array}{l}107,3 \\
\end{array}$ \\
\hline & 5831,3 & 3762,5 & 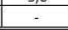 & 5302,5 & the & 20 & \begin{tabular}{|c|c|}
3778,8 \\
\end{tabular} & 4010,1 & 2052,5 & 2052,5 & 55539,6 & \begin{tabular}{|l|l|}
6122,8 \\
\end{tabular} & & & & - & 3680,2 & $\begin{array}{l}23729,8 \\
\end{array}$ \\
\hline \multirow{4}{*}{\multicolumn{4}{|c|}{$\begin{array}{l}\text { FS1 - Flexible Contracts type } 1 \\
\text { FS2- Flexible Contracts type } 2\end{array}$}} & \multirow{4}{*}{\multicolumn{5}{|c|}{$\begin{array}{l}\text { do - Day of event } \\
\text { to - Period of event }\end{array}$}} & & & & & & & & & & \\
\hline & & & & & & & & & & & & & & & & & & \\
\hline & & & & & & & & & & & & & & & & & & \\
\hline & & & & & & & & & & & & & & & & & & \\
\hline
\end{tabular}

The present paper presented a methodology to support decision making concerning demand response programs and contracts adoption. The methodology has been integrated in a decision-support system that is a part of a simulator developed by the authors, and is intended for the use of the players acting in the demand response programs, namely consumers, independent system operator, virtual power players, and curtailment service providers.

The proposed methodology uses machine learning to support DR programs use. This is based on clustering and classification techniques, resulting in a rule base concerning DR programs and contracts use. Consumers performance evaluation methods and tools are also a part of the proposed methodology.

A case study concerning an incident situation that causes an islanded operation was presented. The case study evidences the advantages of using adequate methodologies to manage demand response in this kind of situation.

\section{Acknowledgement}

This work is supported by FEDER Funds through COMPETE program and by National Funds through FCT under the projects FCOMP-01-0124-FEDER: PEst-OE/EEI/UI0760/2011, PTDC/EEA-EEL/099832/2008, PTDC/SEN-ENR/099844/2008, PTDC/SEN-ENR/122174/2010.

and

\section{References}

[1] Sally Hunt, Making Competition Work in Electricity, Published by John Wiley \& Sons, Inc., New York, (2002).

[2] H Aalami, M Moghaddam, G Yousefi, Demand response modeling considering Interruptible/Curtailable loads and capacity market programs, Applied Energy, Elsevier, 87, (2010).

[3] R Walawalkar, S Fernands, N Thakur, K Chevva, Evolution and current status of demand response (DR) in electricity markets: Insights from PJM and NYISO, Energy, Elsevier, 35, (2010). 
[4] M Albadi, E El-Saadany, A summary of demand response in electricity markets, Electric Power Systems Research, 78, (2008).

[5] C Woo, L Greening, Guest editors' introduction - Demand Response Resources: the US and International Experience, Energy, Elsevier, 35, (2010).

[6] P Cappers, C Goldman, D Kathan, Demand response in U.S. electricity markets: Empirical evidence, Energy, Elsevier, 35, (2010).

[7] M Albadi, E El-Saadany, A summary of demand response in electricity markets, Electric Power Systems Research, Elsevier, 78, (2008).

[8] US Department of Energy, Benefits of Demand Response in Electricity Markets and Recommendations for achieving them, Report to the United States Congress, (2006), Available from: http://eetd.lbl.gov/EA/EMS/reports/congress-1252d.pdf, [accessed in May 2011].

[9] J Bushnell, B Hobbs, F Wolak, When It Comes to Demand Response, Is FERC Its Own Worst Enemy?, The Electricity Journal, 22, (2009).

[10] FERC, Final Rule, Order 719, Wholesale Competition in Regions with Organized Electric Markets, 18 CFR Part 35, (2008), available at www.ferc.gov/whats-new/comm-meet/2008/101608/E-1.pdf.

[11] Hugo Morais, Peter Kadar, Pedro Faria, Zita Vale, Hussein Khodr, Optimal scheduling of a renewable micro-grid in an isolated load area using mixed-integer linear programming, Renewable Energy, Elsevier, 35, 151-156 (2010).

[12] Pedro Faria, Zita Vale, Judite Ferreira, DemSi A Demand Response Simulator in the Context of Intensive use of Distributed Generation, IEEE International conference on Systems, Man and Cybernetics (SMC 2010), Istanbul, Turkey.

[13] Pedro Faria, Zita Vale, Joo Soares, Judite Ferreira, Particle Swarm Optimization Applied to Integrated Demand Response Resources Scheduling, IEEE SSCI 2011 (IEEE Symposium Series on Computational Intelligence) CIASG 2011 - Symposium on Computational Intelligence Applications in Smart Grid, Paris, France, 11-15 (2011).

[14] Pedro Faria, Zita Vale, Joo Soares, Judite Ferreira, Demand Response Management in Power Systems Using a Particle Swarm Optimization Approach, IEEE Intelligent Systems, available online: ieeexplore.ieee.org/stamp/stamp.jsp?tp=\&arnumber=5744065\&isnumber $=5196652$

[15] Pedro Faria, Zita Vale, Demand Response in Electrical Energy supply: An Optimal Real Time Pricing Approach, Energy, Elsevier, 36, (2011).

[16] Zita Vale, Hugo Morais, Sergio Ramos, Joo Soares, Pedro Faria, Using Data Mining Techniques to Support DR Programs Definition in Smart Grids, IEEE Power and Energy Society General Meeting 2011, Detroit, Michigan, USA, 24 - 29 (2011).

[17] Tiago Sousa, Hugo Morais, Zita Vale, Pedro Faria, Joo Soares, Intelligent Energy Resource Management Considering Vehicle-to-Grid: A Simulated Annealing Approach, IEEE Transaction on Smart Grid, 3, (2012) .

[18] S Borenstein, M Jaske, A Rosenfeld, Dynamic Pricing, Advanced Metering and Demand Response in Electricity Markets, October (2002), Available from:
http://www.ucei.berkeley.edu/PDF/csemwp105.pdf, [accessed in May 2011].

[19] R Arnold, Economics, 8th ed. USA: Thomson, ISBN 9780324595420, (2007)

[20] Ian Witten, Eibe Frank, Mark Hall, Data Mining: Practical Machine Learning Tools and Techniques, 3rd ed., Elsevier, (2011).

[21] D. Nguyen, M. Negnevitsky, M. de Groot, "A new and separated market for demand response in restructured power systems, Power Systems Conference and Exposition (PSCE), 20-23 (2011).

[22] EnerNoc staff, The demand response baseline, version 3.0, available online: http://www.naesb.org/pdf4/dsmee100608enernoc_2.pdf, (2008).

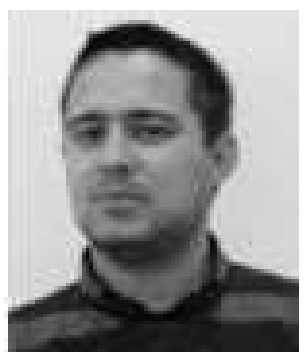

Pedro Faria received the $\mathrm{BSc}$ and Master degrees in Electrical Engineering from the Polytechnic Institute of Porto (ISEP/IPP), Portugal in 2008 and 2011 respectively. $\mathrm{He}$ is an Assistant Researcher at GECAD Knowledge Engineering and Decision-Support Research Center and a PhD student. His research interests include demand response, smart grids, and electricity markets.

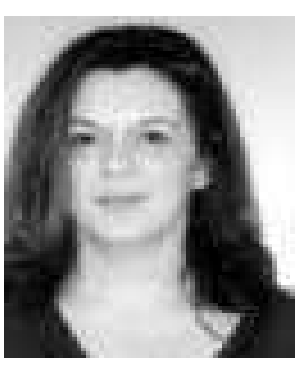

Zita A. Vale is the director of the Knowledge Engineering and Decision Support Research Center (GECAD) and a professor at the Polytechnic Institute of Porto. She received her diploma in Electrical Engineering in 1986 and her $\mathrm{PhD}$ in 1993, both from University of Porto. Her main research interests concern Artificial Intelligence (A.I.) applications to Power System operation and control, Electricity Markets, Distributed Generation, and Smart Grids. 